\title{
Cystic Nonfunctioning Pancreatic Endocrine Neoplasm Presenting Communication with Main Pancreatic Duct
}

\author{
Keiko Kamei Takeo Yasuda Wataru Shinzaki Shumpei Satoi Takashi Ueda \\ Yoshifumi Takeyama
}

Department of Surgery, Kinki University School of Medicine, Osakasayama, Japan

A 57-year-old woman was suspected of having a pancreatic tumor by ultrasonography at medical checkup. She was asymptomatic and laboratory data, including tumor markers, were normal. Abdominal computed tomography demonstrated a cystic tumor (about $3 \mathrm{~cm}$ in diameter) in the pancreatic tail. The solid lesion of the tumor was enhanced with contrast material (fig. 1). Endoscopic retrograde pancreatography revealed commu-

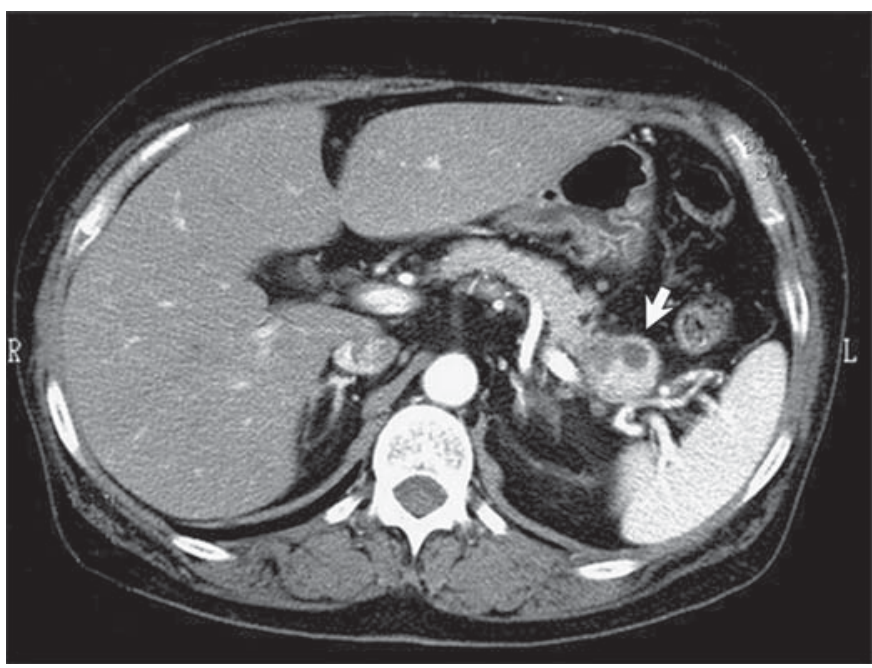

Fig. 1. Abdominal computed tomography demonstrating cystic tumor (about $3 \mathrm{~cm}$ in diameter) in pancreatic tail (arrow). The solid lesion of the tumor was enhanced with contrast material. nication between the main pancreatic duct and cystic tumor (fig. 2). Under the diagnosis of mucinous cystic neoplasm, distal pancreatectomy was performed. Immunohistochemical examination showed positivity for the neuroendocrine markers (chromogranin A, neuron-specific enolase, and synaptophysin). The patient remained well 9 months after the operation.

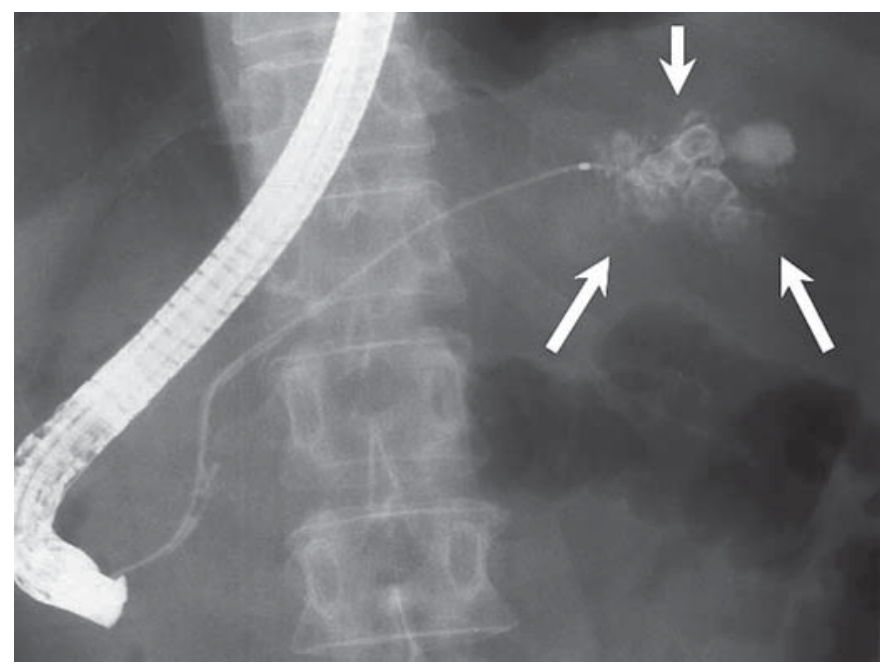

Fig. 2. Endoscopic retrograde pancreatography showing communication between main pancreatic duct and cystic tumor (arrows).

\section{KARGER}

Fax +41613061234 E-Mail karger@karger.ch www.karger.com
(C) 2009 S. Karger AG, Basel

0253-4886/09/0261-0025\$26.00/0

Accessible online at:

www.karger.com/dsu
Keiko Kamei

Department of Surgery, Kinki University School of Medicine

377-2 Ohno-higashi

Osakasayama 589-8511 (Japan)

Tel. +81 72366 0221, Fax +81 72367 7771, E-Mail Keiko-Kamei@surg.med.kindai.ac.jp 
Cystic lesions of the pancreas are sometimes difficult to diagnose preoperatively [1]. In pancreatic endocrine neoplasm (PEN), solid and cystic change occurs rarely due to the abundant vascular supply. Very few cases of cystic nonfunctioning PEN have been reported in the international literature [2-4]. Moreover, cystic PEN is thought to have no communication with the main pancreatic duct, so this case is extremely rare. Hemorrhage or necrosis is considered to be the initial event leading to cyst development in PEN, and degenerative change might cause a communication/fistula with the main pancreatic duct.
References
Garcea G, Ong SL, Rajesh A, Neal CP, Pollard CA, Berry DP, Dennison AR: Cystic lesions of the pancreas. A diagnostic and management dilemma. Pancreatology 2008;8:236251.

2 Schwartz RW, Munfakh NA, Zweng TN, Strodel WE, Lee E, Thompson NW: Nonfunctioning cystic neuroendocrine neoplasms of the pancreas. Surgery $1994 ; 115$ : 645-649.
3 Kato K, Kondo S, Ambo Y, Omi M, Hirano S, Morikawa T, Okushiba S, Katoh H, Fujita M, Shimizu M: Nonfunctioning endocrine tumor of the pancreas with extrapancreatic growth and cyst formation: report of a case. Surg Today 2000;30:651-654.

4 Li Destri G, Reggio E, Veroux M, Lanzafame S, Puleo S, Minutolo V: A rare cystic nonfunctioning neuroendocrine pancreatic tumor with an unusual presentation. Tumori 2006;92:260-263.
Kamei/Yasuda/Shinzaki/Satoi/Ueda/ Takeyama 